\title{
Revisiting the Utility of Dilated Fundus Exams in Patients with Neovascular Age-Related Macular Degeneration Receiving Regular Intravitreal Injections
}

This article was published in the following Dove Press journal: Clinical Ophthalmology

Fares Antaki $\mathbb{D}^{1,2}$

Daniel Milad (D) 3

Ali Dirani (iD ${ }^{4}$

'Department of Ophthalmology, Université de Montréal, Montreal, QC, Canada;

${ }^{2}$ Centre Universitaire d'Ophtalmologie (CUO), Hôpital Maisonneuve-Rosemont, CIUSSS de l'Est-De-l'île-De-Montréal, Montreal, QC, Canada; ${ }^{3}$ Faculty of Medicine, Université Laval, Quebec City, QC, Canada; ${ }^{4}$ Department of Ophthalmology, Centre Universitaire d'Ophtalmologie, Hôpital du SaintSacrement, CHU de Québec - Université Laval, Quebec City, QC, Canada
Correspondence: Ali Dirani

Department of Ophthalmology, Centre

Universitaire d'Ophtalmologie, Hôpital du

Saint-Sacrement, CHU de Québec -

Université Laval, Quebec City, QC,

Canada

Email drdirani@gmail.com

\begin{abstract}
Patients receiving regular anti-vascular endothelial growth factor (anti-VEGF) intravitreal injections for neovascular age-related macular degeneration (nAMD) routinely undergo dilated fundus examination (DFE) at each visit. In this paper, we review the current evidence on the utility of DFE in guiding treatment of established patients with nAMD and discuss novel treatment algorithms that defer DFE assessments with the advent of optical coherence tomography (OCT). We also debate on the value of DFE in the current sanitary context of COVID-19 and highlight important clinical scenarios where it must be performed. Keywords: age-related macular degeneration, dilated fundus exam, intravitreal injections, COVID-19, optical coherence tomography
\end{abstract}

The use of anti-vascular endothelial growth factor (anti-VEGF) intravitreal injections has revolutionized the treatment of neovascular age-related macular degeneration (nAMD) as we know it and has rapidly become the standard of care. ${ }^{1}$ Patients receiving regular injections routinely undergo a dilated fundus examination (DFE) and optical coherence tomography (OCT) at every visit, in order to guide the treatment interval. The rationale for performing a DFE at every visit is to "to detect subtle clinical signs of choroidal neovascularisation (CNV)" like "small areas of hemorrhage, hard exudates, subretinal fluid, macular edema, subretinal fibrosis, or pigment epithelial elevation" as stated by the most recent American Academy of Ophthalmology (AAO)'s Preferred Practice Pattern for AMD. ${ }^{2}$

This past year, ophthalmology has faced many difficult challenges brought forward by the COVID-19 pandemic. With the second wave of COVID-19 upon us, many of these challenges remain and new challenges have come forward. This has sparked a renewed interest in improving existing treatment regimens for nAMD with the purpose of providing quality ophthalmic care without increasing the risk of viral spread among eye care providers and patients. ${ }^{3}$ Close physical proximity (eg during slit-lamp examination) has been shown to increase the risk of transmission of respiratory viruses among humans. ${ }^{4,5}$ The use of slit-lamp shields has been shown to reduce droplet transmission in various experimental setups ${ }^{6,7}$ and is recommended by major ophthalmological societies like the $\mathrm{AAO}{ }^{8}$ With slit-lamp examination being a potentially high-risk scenario for transmission and a potential hurdle for clinic efficiency, its utility is being questioned. ${ }^{3,9}$ 
The HARBOR trial that studied ranibizumab for nAMD showed no difference in treatment outcomes between monthly dosing and the OCT-only guided monthly pro re nata (PRN) dosing. ${ }^{10}$ Post-hoc analyses of that trial suggested that macular hemorrhages without OCT-detectable fluid may not require treatment. These analyses found no evidence that missed hemorrhages impacted visual acuity outcomes after two years. ${ }^{11}$ The value of detecting clinical signs of $\mathrm{CNV}$ in eyes that do not meet retreatment criteria (visual loss or evidence of disease activity on OCT) is questionable. In clinical practice, Trivizki and colleagues have recently demonstrated that eliminating visual acuity (VA) and DFE assessments for patients receiving OCT-guided retreatments for nAMD increased clinic efficiency by doubling patient throughput and decreasing encounter time by $50 \%$ per patient. ${ }^{9}$ Additional advantages included decreased cost per patient, greater clinic efficiency and greater daily revenue for the practice. ${ }^{9}$

Earlier this year, our group proposed a treatment regimen that does not completely eliminate VA and DFE assessments. Instead, the treat-and-plan (TAP) regimen proposes two visit types: assessment visits during which VA, DFE and OCT are obtained, and in-and-out injection visits where only injections are performed without OCT or examination. ${ }^{3}$ Assessment visits guide the ophthalmologist in selecting the appropriate fixed-interval injection regimen (for example, every 4 weeks, 6 weeks or 8 weeks) for the next 3 injections. The first injection is carried out during the same visit and the subsequent two injections are performed using the in-and-out injection visit model. During in-and-out injections visits, prior to every injection, patients must be specifically asked about symptoms of pain and photophobia, new floaters, flashes or change in vision (decrease in acuity or change in visual field) as those could be suggestive of intraocular inflammation or retinal tears and detachment. Patients reporting any of those symptoms must undergo DFE. The efficacy of the TAP regimen is based on previous evidence on the high intra-individual predictability of retreatment need with intravitreal injections for nAMD. ${ }^{12,13}$ TAP shares similarities with the previouslypublished "observe-and-plan" (OAP) regimen that has been shown to be effective in maintaining good VA for up to 2 years despite the lower number of assessment visits compared to traditional PRN and treat and extend regimens. $^{12,13}$
While omitting regular DFE does not seem to affect visual outcomes in nAMD, some risks associated to intravitreal injections warrant an occasional exam in patients receiving regular treatments. Currently, no concluding recommendation exists on pupillary dilation prior to intravitreal injections. ${ }^{14}$ However, dilation may be useful in assessing central retinal artery perfusion after injection. In our experience, gross visual acuity examination by finger counting or hand motion assessment is sufficient to check for perfusion. If no perception of light (NPL) is found in the treated eye, should the intraocular pressure be high, non-perfusion is diagnosed without needing to visualise the optic nerve, and immediate care is initiated. This approach is consistent with the practice patterns of the majority of the retinal specialists in the United States. ${ }^{15}$

Patients receiving novel anti-VEGF agents like brolucizumab must be examined at every visit given the risk of retinal vasculitis and intraocular inflammation. ${ }^{16}$ Otherwise, in patients receiving aflibercept, bevacizumab, or ranibizumab, clinicians can consider performing DFE at scheduled intervals (like in the TAP regimen) or only in patients with an objective or subjective decline in VA despite a stable OCT appearance.

For all the aforementioned reasons, we believe that clinicians should consider omitting regular DFE in most established patients receiving regular anti-VEGF injections for nAMD. Clinical history and VA can identify patients who require a DFE during injection-only clinics. The benefits of avoiding high-risk scenarios for COVID19 transmission (like slit-lamp examination) and decreasing waiting room congestion by improved clinic efficiency cannot be overlooked during this pandemic.

\section{Author Contributions}

All authors made substantial contributions to conception and design, acquisition of data, or analysis and interpretation of data; took part in drafting the article or revising it critically for important intellectual content; agreed to submit to the current journal; gave final approval of the version to be published; and agree to be accountable for all aspects of the work.

\section{Funding}

No funding was received for this research.

\section{Disclosure}

The authors declare that they have no conflicts of interest for this work. 


\section{References}

1. Finger RP, Daien V, Eldem BM, et al. Anti-vascular endothelial growth factor in neovascular age-related macular degeneration a systematic review of the impact of anti-VEGF on patient outcomes and healthcare systems. BMC Ophthalmol. 2020;20(1):294. doi:10.1186/s12886-020-01554-2

2. Flaxel CJ, Adelman RA, Bailey ST, et al. age-related macular degeneration preferred practice pattern(R). Ophthalmology. 2020;127(1):P1-P65.

3. Antaki F, Dirani A. Treating neovascular age-related macular degeneration in the era of COVID-19. Graefes Arch Clin Exp Ophthalmol. 2020;258(7):1567-1569. doi:10.1007/s00417-020-04693-w

4. Kutter JS, Spronken MI, Fraaij PL, Fouchier RA, Herfst S. Transmission routes of respiratory viruses among humans. Curr Opin Virol. 2018;28:142-151. doi:10.1016/j.coviro.2018.01.001

5. Chu DK, Akl EA, Duda S, et al. Physical distancing, face masks, and eye protection to prevent person-to-person transmission of SARS-CoV-2 and COVID-19: a systematic review and meta-analysis. Lancet. 2020;395(10242):1973-1987. doi:10.1016/ S0140-6736(20)31142-9

6. Shah SH, Garg AK, Patel S, Yim W, Jokerst JV, Chao DL. Assessment of respiratory droplet transmission during the ophthalmic slit-lamp exam: a particle tracking analysis. $\mathrm{Am} J$ Ophthalmol. 2021;222:76-81. doi:10.1016/j.ajo.2020.08.046

7. Ong SC, Razali MAB, Shaffiee L, et al. Do slit-lamp shields and face masks protect ophthalmologists amidst COVID-19? Ophthalmology. 2020;127(10):1427. doi:10.1016/j.ophtha.2020.06.031

8. American Academy of Ophthalmology. Important coronavirus updates for ophthalmologists; 2020. Available from: https://www.aao.org/headline/ alert-important-coronavirus-context. Accessed February 27, 2021.
9. Trivizki O, Karp MR, Chawla A, Yamanuha J, Gregori G, Rosenfeld PJ. Eliminating visual acuity and dilated fundus exams improves cost efficiency of performing OCT-guided intravitreal injections. Am J Ophthalmol. 2020;219:222-230. doi:10.1016/j. ajo.2020.06.028

10. Ho AC, Busbee BG, Regillo CD, et al. Twenty-four-month efficacy and safety of $0.5 \mathrm{mg}$ or $2.0 \mathrm{mg}$ ranibizumab in patients with subfoveal neovascular age-related macular degeneration. Ophthalmology. 2014;121(11):2181-2192. doi:10.1016/j.ophtha.2014.05.009

11. Patel Y, Miller DM, Fung AE, Hill LF, Rosenfeld PJ. Are dilated fundus examinations needed for OCT-guided retreatment of exudative age-related macular degeneration? Ophthalmol Retina. 2020;4 (2):141-147. doi:10.1016/j.oret.2019.09.006

12. Gianniou C, Dirani A, Ferrini W, et al. Two-year outcome of an observe-and-plan regimen for neovascular age-related macular degeneration: how to alleviate the clinical burden with maintained functional results. Eye (Lond). 2015;29(3):450-451. doi:10.1038/eye.2014.321

13. Parvin P, Zola M, Dirani A, Ambresin A, Mantel I. Two-year outcome of an observe-and-plan regimen for neovascular age-related macular degeneration treated with Aflibercept. Graefes Arch Clin Exp Ophthalmol. 2017;255(11):2127-2134. doi:10.1007/s00417-017-3762-2

14. Grzybowski A, Told R, Sacu S, et al. 2018 update on intravitreal injections: euretina expert consensus recommendations. Ophthalmologica. 2018;239(4):181-193. doi:10.1159/000486145

15. Green-Simms AE, Ekdawi NS, Bakri SJ. Survey of intravitreal injection techniques among retinal specialists in the United States. $\mathrm{Am}$ J Ophthalmol. 2011;151(2):329-332. doi:10.1016/j.ajo.2010.08.039

16. Baumal CR, Spaide RF, Vajzovic L, et al. Retinal vasculitis and intraocular inflammation after intravitreal injection of brolucizumab. Ophthalmology. 2020;127(10):1345-1359. doi:10.1016/j.ophtha.2020.04.017
Clinical Ophthalmology

\section{Publish your work in this journal}

Clinical Ophthalmology is an international, peer-reviewed journal covering all subspecialties within ophthalmology. Key topics include: Optometry; Visual science; Pharmacology and drug therapy in eye diseases; Basic Sciences; Primary and Secondary eye care; Patient Safety and Quality of Care Improvements. This journal is indexed on PubMed

\section{Dovepress}

Central and CAS, and is the official journal of The Society of Clinical Ophthalmology (SCO). The manuscript management system is completely online and includes a very quick and fair peer-review system, which is all easy to use. Visit http://www.dovepress.com/ testimonials.php to read real quotes from published authors. 